\title{
THE EFFECT OF METFORMIN ON MARKERS OF BONE METABOLISM IN MALE PATIENTS WITH TYPE 2 DIABETES MELLITUS
}

\author{
Fayez Elkenawy Mohamed ${ }^{1}$, Fathy Elsayed Abdelgawad ${ }^{2}$, Tamer Saber $^{3}$, Ahmad A.G. Ibrahim ${ }^{4}$ \\ ${ }^{1}$ Internal Medicine Department, Faculty of Medicine, Mansoura University. \\ ${ }^{2}$ Medical biochemistry department, Faculty of Medicine, Al-Azhar University. \\ ${ }^{3}$ Internal Medicine Department, Faculty of Medicine, Zagazig University. \\ ${ }^{4}$ Rheumatology Department, Faculty of Medicine, Benha University.
}

\begin{abstract}
Corresponding Author:
Tamer Saber,

Tel $\quad+966562093063$.

Email:
\end{abstract}

tsaber7@gmail.com

\section{a}

Background: Bone is a vital, dynamic connective tissue that throughout life is continuously remodeled by balanced bone formation and resorption. It has been reported that diabetes and its metabolic disturbances and medications lead to important alterations in bone metabolism. The objective of this study is to determine the effect of metformin on markers of bone metabolism [Nterminal cross-linked telopeptide of type- 1 collagen (NTx) and osteocalcin] in male patients with type 2 diabetes mellitus. Methods: a case-controlled study was conducted on 100 male type 2 diabetic patients. Their ages ranged from (35-50years) living in Saudi Arabia at Al-Madinah Al- Monawara Province. They were on oral antidiabetic drugs, divided into two groups according to treatment with metformin. Routine laboratory measurements included serum levels of fasting glucose, $\mathrm{HbAlc}$, total calcium, inorganic phosphorus, total alkaline phosphatase and intact parathyroid hormone, osteocalcin was measured as a bone formation marker. Second-morning void urine was collected from patients to measure urinary NTx as a resorptive marker. Results: there was no significant difference between the two groups as regard the clinical, biochemical and diabetic control parameters(age, BMI, duration of diabetes, FBS, HbA1c, calcium, Phosphorus, total alkaline phosphatase, and iPTH). No statistical differences in osteocalcin $(\mathrm{ng} / \mathrm{ml})$ between the two groups $(13.3 \pm 1.43$ vs $13.0 \pm 1.4$, $\mathrm{P}$-value $=0.348)$. The mean of NTx (nM BCE/mM creatinine) of metformin group 1 was $(29.6 \pm 7.8)$ lower than that of non-metformin group $2(44.6 \pm 6.1)$ with highly significant differences between the two groups $(\mathrm{P}=0.000)$.Conclusion: metformin may have a favorable effect on bone metabolism in type 2 diabetic males through a decrease of bone resorption marker, but more researches are required to know the overall impact of this medication on bone health on the long term. Keywords: Type2diabetes, Metformin, Bone turnover markers, Osteoporosis.

\section{INTRODUCTION}

B one is a dynamic connective tissue that is continuously remodeled by the processes of bone formation and bone resorption, and these two processes are normally coupled ${ }^{[1]}$. An imbalance in bone resorption relative to formation results in negative bone balance at the tissue level. This may lead to osteoporosis, a common skeletal disease characterized by reduced bone mass, deterioration of bone microarchitecture, and increased susceptibility to fractures ${ }^{[2]}$.

Biochemical markers of bone turnover comprise serum and urinary concentrations of enzymes and bone matrix proteins that are released into the circulation during bone remodeling ${ }^{[3]}$. The most sensitive markers include serum osteocalcin, bone specific alkaline phosphatase, the N-terminal propeptide of type I collagen for bone formation, and the crosslinked C- (CTX) and $\mathrm{N}$ - (NTX) telopeptides of type I collagen for bone resorption ${ }^{[4,5]}$.

Diabetes and its metabolic disturbances may lead to important alterations in bone metabolism [6]. Metformin is widely prescribed as a first-line therapy for patients with type 2 diabetes mellitus ${ }^{[7]}$. In contrast to thiazolidinediones, another oral antidiabetic drug which has adverse effects on the skeleton ${ }^{[8]}$, several studies have documented that metformin is osteogenic in vitro ${ }^{[9]}$. 
The objective of this study is to determine the effect of metformin on markers of bone turnover (NTx and osteocalcin) in male patients with type 2 diabetes mellitus.

\section{SUBJECTS AND METHODS}

This work was conducted on 100 male type 2 diabetic patients. Their ages ranged from (3550years) living in Saudi Arabia at AlMadinah Al- Monawara Province. Patients were selected at medical outpatient clinics of Islamic University Medical Center during follow-up. The included patients were classified into 2 groups: Group (1): Included 50 male type 2 diabetic patients treated with metformin alone in a dose of 1500- 2000 $\mathrm{mg} /$ day in two divided doses. Group (2): Included 50 male type 2 diabetic patients treated with oral anti-diabetic drugs other than metformin [sulphonylurea and/or dipeptide peptidase 4 inhibitors]. The two groups were matched for age and duration of diabetes. The included patients were diagnosed with type 2 diabetes according to American Diabetes Association (ADA) 2010 Criteria [10].

Exclusion criteria: Patients who known to have diseases or conditions that could potentially have effects on bone metabolism, such as Cushing's syndrome, hyperthyroidism, hyperprolactinemia, hypogonadism, hyperparathyroidism, renal failure, malabsorption, hypovitaminosis $\mathrm{D}$, chronic alcohol intake or heavy smoking $(>10$ cigarettes/day), patients treated with drugs such as thyroid hormones, steroids, vitamin $\mathrm{D}$, calcium and magnesium that could interfere with bone metabolism, and patients with known macro or microangiopathy were excluded from the study. Patients with uncontrolled diabetes and HbA1c above 7.5 gm\% and patients treated with thiazolidinediones were also excluded from the study.

\section{Laboratory measurements}

After $8-10$ hours overnight fast, blood samples were obtained from the antecubital vein and the serum was separated by centrifugation. Laboratory measurements included serum levels of fasting glucose, total calcium, inorganic phosphorus and total alkaline phosphatase measured following routine biochemical laboratory protocols using automated Siemens Dimension (RxL Max) clinical chemistry system. Intact PTH test is performed using the Vitros Intact PTH Reagent Pack and the Vitros intact PTH calibrators on the Vitros immunodiagnostic system. This kits supplied by Ortho-Clinical Diagnostics, USA, using Vitros 3600 (Ortho clinical Diagnostic, Johanson and Johanson Co, USA) ${ }^{[11,12]}$. Blood samples with EDTA were also obtained from patients to measure HbA1c determined using Siemens DCA analyzer for the quantitative assay for $\mathrm{HbA} 1 \mathrm{c}$ in blood. ${ }^{[13]}$. A second-morning void urine sample was collected from patients for quantitative measurement NTx using the Vitros NTx Reagent Pack and the Vitros NTx calibrators on the Vitros immunodiagnostic system. This kits supplied by Ortho-Clinical Diagnostics, USA, using vitros 3600(Ortho clinical Diagnostic, Johanson and Johanson Co, USA) ${ }^{[14]}$. Analyte results are quoted in units of nanomoles bone collagen equivalents per liter (nM BCE). Test values are corrected for urinary dilution by urinary creatinine analysis and expressed in nanomoles bone collagen equivalents per liter per millimole creatinine per liter[nMBCE/mMcreatinine] as shown in the following equation: NTx $($ nMBCE $/$ mMcreatinine $)=$ NTx $(\mathrm{nMBCE}) /$ Urinary creatinine $(\mathrm{mM}){ }^{[15]}$. The Human osteocalcin ELISA research-use-only kit is to be used for the quantitative determination of intact human osteocalcin in serum and plasma samples using 96-well plates and a microplate reader ${ }^{[16]}$

\section{STATISTICAL ANALYSIS}

Descriptive data are expressed as mean \pm SD. Statistical comparisons of data obtained from both groups in the study were performed using paired t-tests. P-values $<0.05$ were considered to be statistically significant.

\section{RESULTS}

The clinical and biochemical characteristics of the study population categorized according to the treatment with metformin are presented in Table 1. No statistically significant difference in the age between two groups $(40.9 \pm 4.2$ vs $41.92 \pm 4.5$ years, $\mathrm{P}=0.176)$. No statistically significant difference in the BMI between the two groups $(31.9 \pm 1.6$ vs $31.65 \pm 1.5 \mathrm{~kg} / \mathrm{m} 2, \mathrm{P}=0.442$ ). No statistically significant difference in the 
duration of diabetes between the two groups ( $4.14 \pm 0.48$ vs $4.19 \pm 0.46$ years, $\mathrm{P}=0.528$ ).

No statistically significant difference in the fasting glucose between the two groups (124.5 \pm 18.4 vs $117.7 \pm 15.8 \mathrm{mg} \%, \mathrm{P}=0.639)$. The mean of HbA1c $(\mathrm{g} / \mathrm{dl})$ of group1 was (7.11 \pm 0.38$)$ is comparable with that of group2 $(7.06 \pm 0.36 \mathrm{~g} / \mathrm{dl}) \quad$ with no statistically significant difference $\mathrm{P}=0.066$.

The mean of iPTH $(\mathrm{pg} / \mathrm{ml})$ of group1 was $(38.9 \pm 4.4)$ is comparable with that of group2
$(39.5 \pm 3.8)$ with no statistically significant difference $\quad(\mathrm{P}=0.439)$. No statistically significant difference in serum calcium between the two groups $(8.8 \pm 0.58$ vs 8.7 $\pm 0.53 \mathrm{mg} / \mathrm{dl}, \quad \mathrm{P}=0.383)$. No statistically significant difference in serum Phosphorus between the two groups $(4.08 \pm 0.48$ vs $4.12 \pm 0.45 \mathrm{mg} / \mathrm{dl}, \mathrm{P}=0.697)$. No statistically significant difference in the mean of total alkaline phosphatase between the two groups $(88.96 \pm 14.9$ vs $87.66 \pm 13.6 \mathrm{U} / \mathrm{L}, \mathrm{P}=0.461)$.

Table 1: Clinical and biochemical parameters in both groups

\begin{tabular}{|c|c|c|c|c|}
\hline Variable & $\begin{array}{l}\text { (Group1) Diabetes } \\
\text { with metformin } \\
\text { No=50 }\end{array}$ & $\begin{array}{l}\text { (Group2) } \\
\text { Diabetes with OAD other } \\
\text { than metformin } \\
\text { No=50 }\end{array}$ & t- test & P-value \\
\hline Age (years) & $40.9 \pm 4.2$ & $41.92 \pm 4.5$ & 1.373 & 0.176 \\
\hline BMI (kg/m2) & $31.9 \pm 1.6$ & $31.65 \pm 1.5$ & -0.775 & 0.442 \\
\hline $\begin{array}{l}\text { Duration of diabetes } \\
\text { (years) }\end{array}$ & $4.14 \pm 0.48$ & $4.19 \pm 0.46$ & 0.636 & 0.528 \\
\hline Fasting glucose (mg/dl) & $124.5 \pm 18.4$ & $117.7 \pm 15.8$ & 0.472 & 0.639 \\
\hline HbA1c (g/dl) & $7.11 \pm 0.38$ & $7.06 \pm 0.36 \mathrm{~g} / \mathrm{dl}$ & -2.04 & 0.066 \\
\hline iPTH (pg/ml) & $38.9 \pm 4.4$ & $39.5 \pm 3.8$ & 0.780 & 0.439 \\
\hline Calcium(mg/dl) & $8.8 \pm 0.58$ & $8.7 \pm 0.53$ & -0.881 & 0.383 \\
\hline Phosphorus (mg/dl) & $4.08 \pm 0.48$ & $4.12 \pm 0.45$ & 0.392 & 0.697 \\
\hline $\begin{array}{ll}\text { Total } & \text { alkaline } \\
\text { phosphatase } & (\mathrm{U} / \mathrm{L})\end{array}$ & $88.96 \pm 14.9$ & $87.66 \pm 13.6$ & -0.743 & 0.461 \\
\hline
\end{tabular}

\section{*P $<0.05$ : Significant differences}

Osteocalcin and NTx data are presented in Table 2. The mean of osteocalcin $(\mathrm{ng} / \mathrm{ml})$ of group1 was $(13.3 \pm 1.43)$ is comparable with that of group2 (13.0 \pm 1.4$)$. No statistically significant difference in osteocalcin between the two groups $(\mathrm{P}=0.348)$ Figure 1 . The mean of NTx (nM BCE/mM creatinine) of group1 was $(29.6 \pm 7.8)$ is lower than that of group2 (44.6 \pm 6.1$)$. There is a highly significant difference between the two groups in urinary NTx $(\mathrm{P}=0.000)$ Table 2 and Figure 1.

Table 2: Osteocalcin (ng/ml) and NTx (nM BCE/mM creatinine) of patients in both groups

\begin{tabular}{|c|c|c|c|c|c|}
\hline Variable & $\begin{array}{l}\text { (Gro } \\
\text { No }=5\end{array}$ & & $\begin{array}{l}(\mathrm{Gr} \\
\mathrm{No}=\end{array}$ & & $\begin{array}{l}\text { P- } \\
\text { value }\end{array}$ \\
\hline NTx & $\begin{array}{l}29.6 \\
7.8\end{array}$ & \pm & $\begin{array}{l}44.6 \\
6.1\end{array}$ & \pm & 0.000 \\
\hline Oste & $\begin{array}{l}13.3 \\
1.43\end{array}$ & \pm & $\begin{array}{l}13.0 \\
1.4\end{array}$ & \pm & 348 \\
\hline
\end{tabular}

$* \mathbf{P}<0.05$ : Significant differences
Figure1: Diagram of osteocalcin and NTx means between 2 groups

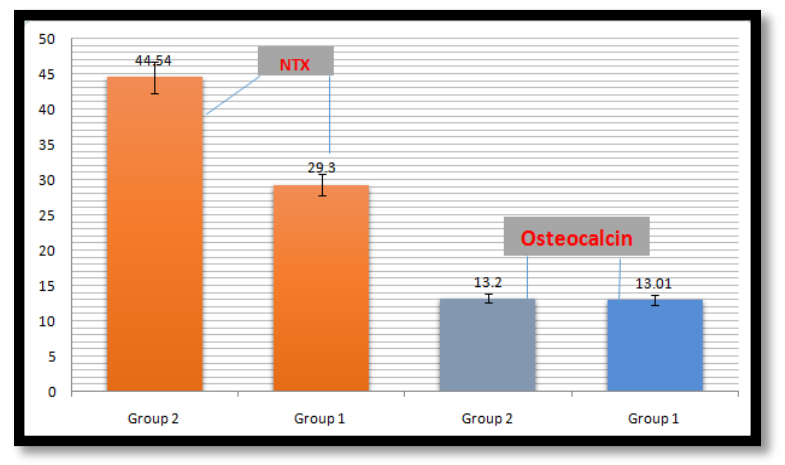

\section{DISCUSSION}

The incidence of type 2 diabetes is increasing all over the world, more so in the Saudi Arabia. Osteoporosis is more likely to be seen in the elderly in association with chronic diseases like diabetes $\left[17,{ }^{18}\right.$. An epidemiological analysis showed that $30.7 \%$ of healthy Saudi men, 50-79 years of age are osteoporotic ${ }^{[19]}$. In Saudi Arabia, there are 
approximately 8,768 femoral fractures each year costing billions, bone health is becoming a serious concern in the kingdom. ${ }^{[20]}$. A better understanding of the factors that determine bone strength in diabetes is needed.

Biochemical markers of bone turnover, involve dynamic molecules and, therefore, are helpful in evaluating and monitoring bone metabolism over short intervals. The most sensitive markers include serum osteocalcin, bone specific alkaline phosphatase, the Nterminal propeptide of type I collagen for bone formation, and the crosslinked C- (CTX) and N- (NTX) telopeptides of type I collagen for bone resorption ${ }^{[4,5]}$.

Type I collagen is predominant in the extracellular matrix of bone. Cross-linked Ntelopeptides (NTx), which is formed during the process of bone resorption by osteoclasts, is proposed to serve as a valid marker of bone resorption ${ }^{[21]}$. Elevated levels of urinary NTx indicate elevated bone resorption ${ }^{[22]}$

Studies showed controversial results about the effects of diabetes and oral antidiabetic drugs (OAD) on bone health ${ }^{[\mathbf{6 , 8}, \mathbf{9}, \text { and 23] }}$.

Metformin, the most widely described OAD for type 2 diabetes mellitus has been shown a favorable effect on bone metabolism by increasing osteoblast proliferation and differentiation and also augmenting type 1 collagen formation in cell culture. In addition, it seems to promote osteoblast differentiation [24].

This study subjects included 100 male patients with type 2 diabetes mellitus without microvascular or macrovascular complications, who were on OAD, divided into two groups according to treatment with metformin, bone turnover markers (NTx as a marker of bone resorption and osteocalcin as a marker of bone synthesis) were measured. There was no significant difference between the two groups as regard the clinical and diabetic control parameters [age, BMI, duration of diabetes, FBS, and $\mathrm{HbA} 1 \mathrm{c}]$.

Patients in the two groups showed no significant differences as regard factors that affect calcium homeostasis [iPTH, calcium, phosphorus and total alkaline phosphatase]. There was statistically significant reduction in the urinary level of NTx in patients receiving metformin $(29.6 \pm 7.8$ vs $44.6 \pm 6.1, \mathrm{p}=0.000)$ and no statistically significant difference in serum level of osteocalcin between the two groups.

Similar results of favorable effects of metformin on bone turnover markers were reported by Zinman et al, ${ }^{[25]}$ and Lierop et al, [26]. Omodele et al demonstrated that treatment with metformin alone improves BMD in osteopenic patients with type 2 diabetes [27]. Vestergaard et al, found that metformin was associated with a reduction in the risk of fracture ${ }^{[28]}$

Chan Wang et al, ${ }^{[29]}$ found that metformin has been shown to enhance osteoblasts differentiation and inhibit osteoclast differentiation in vitro and prevent bone loss in ovariectomized rats. But the mechanisms through which metformin regulates osteoclastogenesis are not known. In their study, they demonstrated that metformin dose-dependently stimulated osteoprotegerin and receptor activator of nuclear factor $\kappa B$ ligand (RANKL) mRNA and protein expression in mouse calvarial osteoblasts and osteoblastic cell line MC3T3-E1. Inhibition of AMP-activated protein kinase (AMPK) and CaM kinase kinase (CaMKK), two targets of metformin, suppressed endogenous and metformin-induced osteoprotegerin secretion in osteoblasts ${ }^{[29]}$.

In conclusion, this study showed that metformin may have a favorable effect on bone metabolism in type 2 diabetic males through a decrease of bone resorption marker, but more researches are required to know the overall impact of this medication on bone health in different patients groups and on the long term.

\section{Conflict of Interests}

The authors declare that there is no conflict of interests regarding the publication of this paper.

\section{REFERENCES}

1. Feng X. and McDonald M: Disorders of Bone Remodeling. Annu Rev Pathol. 2011; 6: 121145.

2. Raisz LG.: Pathogenesis of osteoporosis: concepts, conflicts, and prospects. J Clin Invest. 2005; 115:3318-3325.

3. Seibel M: Molecular markers of bone turnover: biochemical, technical and analytical aspects. Osteoporos Int 2000; 11(Suppl 6):S18 - S29.

4. Garnero P.: Biomarkers for osteoporosis 
management: utility in diagnosis, fracture risk prediction and therapy monitoring. Mol Diagn Ther. 2008;12(3):157-70.

5. Garnero P.: Bone markers in osteoporosis," Current Osteoporosis Reports. 2009; vol. 7, no. 3, pp. 84-90.

6. Suzuki K., Kurose T., and Takizawa S.: Osteoclastic function is accelerated in male patients with type 2 diabetes mellitus. Diab. Res. Clin. Pract. 2005;68,117.

7. Cheng A. and Fantus I.: Oral antihyperglycemic therapy for type 2 diabetes mellitus.CMAJ. 2005; 172:213-226.

8. Lecka-Czernik B.: Bone loss in diabetes: use of anti-diabetic thiazolidinediones and secondary osteoporosis. CurrOsteoporos Rep. 2010; 8:178-184.

9. Kanazawa I., Yamaguchi T., Yano S., Yamauchi M., and Sugimoto T.: Metformin enhances the differentiation and mineralization of osteoblastic MC3T3-E1 cells via AMP kinase activation as well as eNOS and BMP-2 expression. Biochem Biophys Res Commun. 2008; 375:414-419.

10. Expert Committee on the Diagnosis and Classification of Diabetes Mellitus: Report of the Expert Committee on the Diagnosis and Classification of Diabetes Mellitus. Diabetes Care 2010; 33(Suppl 1): S11-S61.

11. Hawker C. and Bella F.: Radioimmunoassay's for intact and carboxyl-terminal parathyroid hormone: clinical interpretation and diagnostic significance. Ann Clin Lab Sci 1980; 10:76-87.

12. Nichols J., Christenson R., Clarke W., Gronowski A., Hammett-Stabler C., Jacobs E., Kasmierczak S., Lewandrowski K., Price C., Sacks D., Sautter R., Shipp G., Sokoll L., Watson I., Winter W., and Zucker M.: National Academy of Clinical Biochemistry Laboratory Medicine Practice Guidelines: Evidence Based Practice for Point of Care Testing. AACC Press: 2006.

13. Knowles B.,Haigh W., Michaud G., and Marchesi V.: A monoclonal antibody- based immunoassay for HbA1c. Diabetes. 1986;35: Suppl.94A.

14. Garnero P.: Comparison of New Biochemical Markers of Bone Turnover in Late Postmenopausal Osteoporotic Women in Response to Alendronate Treatment. J ClinEndocrinolMetab1994; 79:1693-1700.

15. NCCLS. : Evaluation of Precision Performance of Quantitative Measurement Methods; Approved Guideline - Second Edition. NCCLS document EP5-A2 [ISBN 156238-542-9]. NCCLS, 940 West Valley Road, Suite 1400, Wayne, PA19087-1898
USA, 2004.

16. Van Dussen L., Lips P., Everts V., Bravenboer N., Jansen I., Groener J., Maas M., Blokland J., Aerts J., and Hollak C.: Markers of bone turnover in Gaucher disease: modeling the evolution of bone disease. J ClinEndocrinolMetab.2011; 96:2194-2205.

17. Nazrun A., Tzar M., Mokhtar S., and Mohamed I.: A systematic review Of the outcomes of osteoporotic fracture patients after hospital discharge: morbidity, subsequent fractures, and mortality. Ther Clin Risk Manag 2014; $10: 937-48$.

18. Thomas V. Paul and Nihal Thomas: Impact of oral antidiabetic agent agents on bone metabolism. Indian J Med Res 141, April 2015; 385-387.

19. Sadat-Ali M, Al-Habdan IM, Al-Turki HA, Azam MQ. An epidemiological analysis of the incidence of osteoporosis and osteoporosisrelated fractures among the Saudi Arabian population. Ann Saudi Med.2012;3:637-641.

20. Alwahhabi B. Osteoporosis in Saudi Arabia. Are we doing enough? Saudi Med J. 2015 Oct; 36(10): 1149-1150.

21. Delmas PD, Eastell R, Garnero P, Siebel MJ, and Stepan J. The use of biochemical markers of bone turnover in osteoporosis. Committee of scientific advisors of the international osteoporosis foundation. Osteoporosis International. 2000;11(supplement 6):S2-S17.

22. Rosen HN, Dresner-Pollak R, Moses AC, Rosenblatt M, Zeind AJ, Clemens JD, Greenspan SL. Specificity of urinary excretion of cross-linked N-telopeptides of type I collagen as a marker of bone turnover. Calcif Tissue Int. 1994; 54:26-29.

23. Lapane K., Y ang S., Brown M., Jawahar R., Pagliasotti C., and Rajpathak S.: Sulfonylureas and risk of falls and fractures: a systematic review. Drugs Aging 2013; 30 : 527-47.

24. Molinuevo M., Schurman L., McCarthy A., Cortizo A., Tolosa M., and Gangoiti M.: Effect of metformin on bone marrow progenitor cell differentiation: in vivo and in vitro studies. $\mathbf{J}$ Bone Miner Res 2010; 25 : 211-21

25. Zinman B., Haffner S., Herman W., Holman R., Lachin J., Kravitz B., Paul G, Jones N., Aftring R., VibertiG., and Kahn S.: Effect of rosiglitazone, metformin, and glyburide on bone biomarkers in patients with type 2 diabetes. Journal of Clinical Endocrinology and Metabolism. 2010; 95, 134-142.

26. Lierop H., Hamdy N., Van der R., Jonker J., Lamb H., Rijzewijk L., Diamant M., Romijn1 J. Smit J. and Papapoulos S.: Distinct effects of pioglitazone and metformin on circulating 
sclerostin and biochemical markers of bone turnover in men with type 2 diabetes mellitus. European Journal of Endocrinology.2012; 166 711-716.

27. Omodele A., Spencer C. and Solomon S.: Effects of Metformin Alone or in Combination With Insulin on Bone Mineral Density in Osteopenic Patients With Type 2 Diabetes. J Endocrinol Metab. 2014;4(4):89-92.

28. Vestergaard P., Rejnmark L., and Mosekilde L.: Relative fracture risk in patients with diabetes mellitus, and the impact of insulin and oral antidiabetic medication on relative fracture risk. Diabetologia 2005; 48 : 1292-9.

29. Chung W., Hong L., Sheng-Guang C., Jin-Wei H., Chun-Jun S., Xiao-Yung C., Shen Q., KeSheng W., Mei-Ling L., and Yong-Chun Y.: Metformin has been demonstrated to induce the differentiation and mineralization of osteoblasts via activation of the AMPactivated protein kinase signaling. $\mathrm{J}$ bone Mineral met abolism.2012; 30:630 - 637. 